\title{
Assessing for disease: recurrent mycosis fungoides or cutaneous granulomatous drug eruption after mogamulizumab therapy
}

\author{
Daniel S. Martig ${ }^{1} \cdot$ Alina G. Bridges $^{1,2} \cdot$ William R. Macon $^{1}$ (D) \\ Received: 27 July 2020 / Accepted: 5 August 2020 / Published online: 12 August 2020 \\ (C) Springer-Verlag GmbH Germany, part of Springer Nature 2020
}

Keywords Erythroderma $\cdot$ Mycosis fungoides $\cdot$ Mogamulizumab

A 72-year-old man, who had previously been diagnosed with mycosis fungoides (MF) and treated with mogamulizumab, presented for clinical follow-up and was found to have diffuse erythroderma associated with areas of poikiloderma (Fig. 1). A punch biopsy was performed to evaluate for recurrent MF.

Histologic sections of the biopsy showed a superficial dermal granulomatous reaction (Fig. $2 \mathrm{a}-\mathrm{c}$ ). Adjacent to the granulomatous reaction were atypical, small to intermediate-sized lymphocytes with irregular nuclei and angulated cytoplasmic borders. These cells were CD3-positive T cells (Fig. 2d) with co-expression of CD4 (Fig. 2e) and GATA3 (Fig. 2g) and no expression of CD7 (Fig. 2f), T-bet (Fig. 2h), or FOXP3 (Fig. 2i).

Mogamulizumab is a recently approved humanized antiCCR4 monoclonal antibody, which causes cytotoxic effects against cells that express CCR4 on their cell membrane, including MF cells and $\mathrm{T}_{\mathrm{H}} 2 /$ regulatory $\mathrm{T}$ cells. A recent study has shown that patients treated with mogamulizumab can develop a cutaneous granulomatous drug eruption (CGDE) and usually present with erythroderma [1]. Histologically, CGDE can mimic granulomatous MF.

Given the mechanism of this drug, immunohistochemical stains for T-bet, GATA-3, and FOXP3 become useful in discriminating granulomatous MF from mogamulizumabassociated CGDE. T-bet is a T-box transcription factor necessary for the development of $\mathrm{T}_{\mathrm{H}} 1$ cells. GATA-3 is expressed on $\mathrm{T}_{\mathrm{H}} 2$ cells, and this $\mathrm{T}$ cell type is seen in dermatoses and

William R. Macon

macon.william@mayo.edu

1 Department of Laboratory Medicine and Pathology, Mayo Clinic, 200 First Street SW, Rochester, MN 55905, USA

2 Department of Dermatology, Mayo Clinic, 200 First Street SW, Rochester, MN 55905, USA forms the predominant cell in late stage MF and in patients with erythrodermic MF and Sézary syndrome (SS) [2]. Accordingly, the neoplastic cells in tumor stage MF and SS are GATA-3-positive [3]. FOXP3 is strongly expressed by regulatory $\mathrm{T}$ cells and is positive in a significant majority of $\mathrm{T}$ cells in most dermatoses [3]. On the other hand, FOXP3positive T cells comprised less than $10 \%$ of the total lymphocytes in the majority of MF biopsies examined in one study and did not exceed $25 \%$ in any of the specimens [4].

In the case presented, the atypical lymphoid infiltrate showed a CD3+/CD4+/CD7-/GATA3+/T-bet-/FOXP3immunophenotype, which supported involvement by $\mathrm{MF}$ rather than a drug reaction or other cutaneous inflammatory $\mathrm{T}$ cell infiltrate.

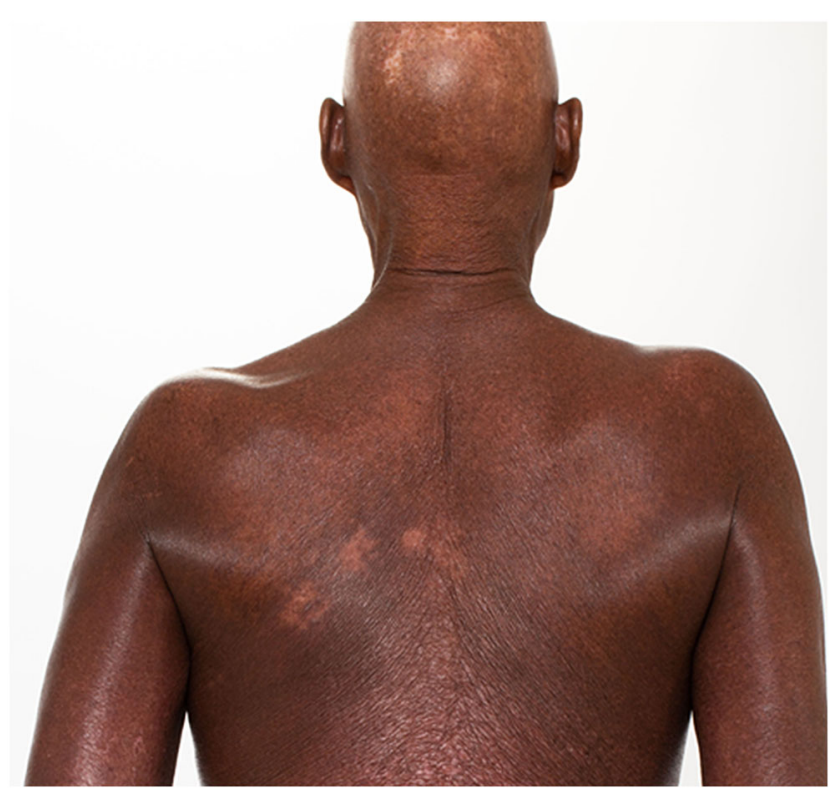

Fig. 1 A 72-year-old man previously treated for mycosis fungoides has developed diffuse erythroderma 
Fig. 2 Histologic sections of the skin biopsy (a-c) show a dermal granuloma and associated atypical small to intermediatesized lymphocytes.

Immunoperoxidase stains indicate the lymphocytes are CD3positive T cells (d) that are CD4positive (e), CD7-negative (f), GATA3-positive (g), Tbetnegative (h), and mostly FOXP3-negative (i)

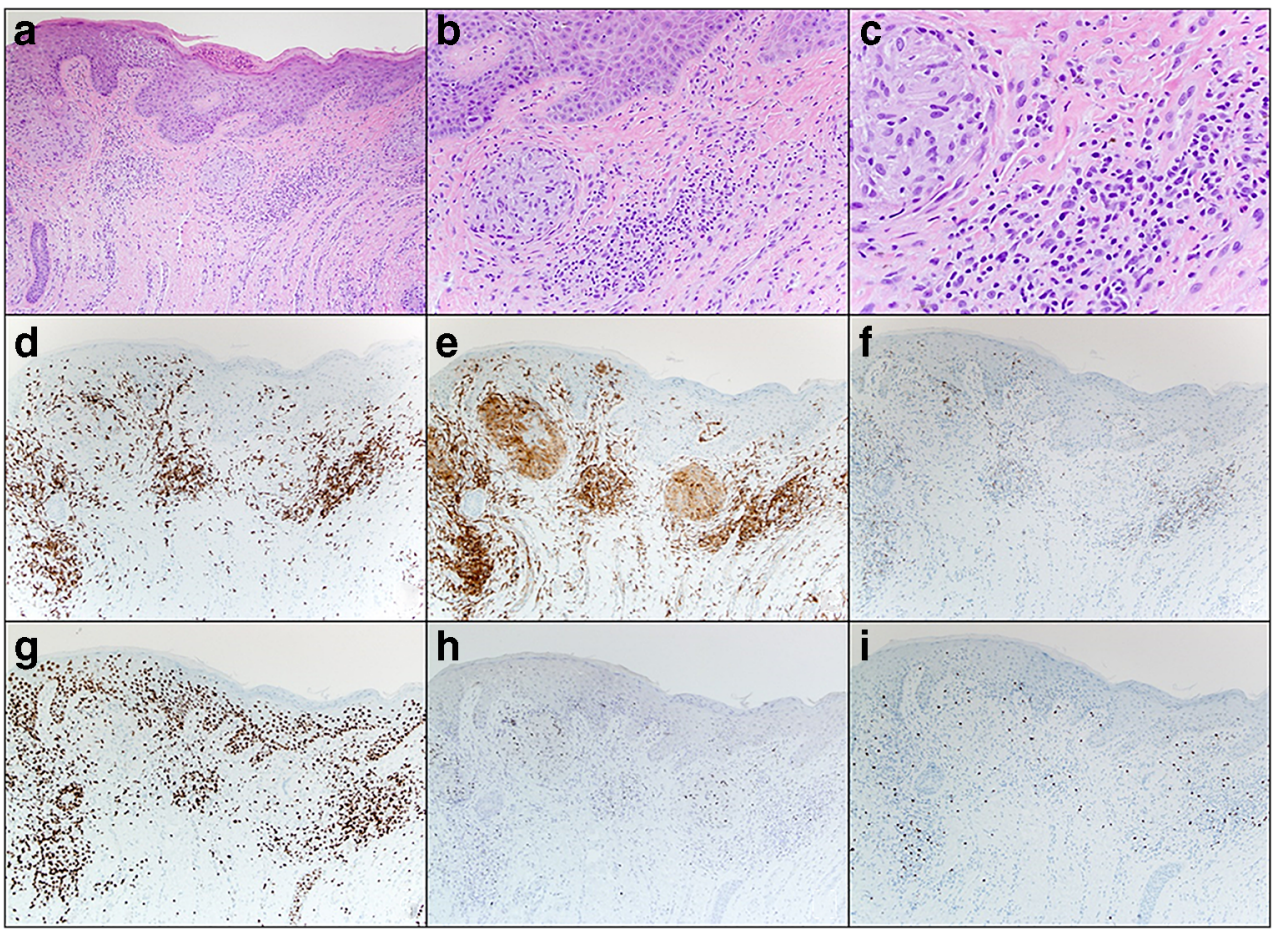

\section{Compliance with ethical standards}

Conflict of interest The authors declare that they have no conflict of interest.

\section{References}

1. Chen L, Carson KR, Staser KW, Mehta-Shah N, Schaffer A, Rosman IS, Musiek A (2019) Mogamulizumab-associated cutaneous granulomatous drug eruption mimicking mycosis fungoides but possibly indicating durable clinical response. JAMA Dermatol 155(8):968971

2. Papadavid E, Economidou J, Psarra A, Kapsimali V, Mantzana V, Antoniou C, Limas K, Stratigos A, Stavrianeas N, Avgerinou G, Katsambas A (2003) The relevance of peripheral blood T-helper 1 and 2 cytokine pattern in the evaluation of patients with mycosis fungoides and Sézary syndrome. Br J Dermatol 148(4):709-718

3. Hsi AC, Lee SJ, Rosman IS, Carson KR, Kelley A, Viele V, Pang X, Musiek A, Scaffer A (2015) Expression of helper T cell master regulators in inflammatory dermatoses and primary cutaneous T-cell lymphomas: diagnostic implications. J Am Acad Dermatol 72(1): 159-167

4. Fried I, Cerroni L (2012) FOXP3 in sequential biopsies of progressive mycosis fungoides. Am J Dermatopathol 34(3):263-265

Publisher's note Springer Nature remains neutral with regard to jurisdictional claims in published maps and institutional affiliations. 